\title{
Desempenho agronômico da cultura do milho e espécies forrageiras em sistema de Integração Lavoura-Pecuária no Cerrado
}

\author{
Agronomic performance of corn and forages species in Crop-Livestock Integration system in the \\ Cerrado
}

\author{
Cássia Maria de Paula Garcia ${ }^{I}$ Marcelo Andreotti ${ }^{I}$ Marcelo Carvalho Minhoto Teixeira Filho ${ }^{I^{*}}$ \\ Salatiér Buzetti ${ }^{I}$ Thiago de Souza Celestrino $^{\mathrm{I}}$ Keny Samejima Mascarenhas Lopes $^{\mathrm{I}}$
}

RESUMO

O consórcio entre culturas leva à competição por fatores de produção como água, luz e nutrientes, porém, atualmente, é comum o cultivo integrado do milho com forrageiras para recuperação e renovação de pastagens degradadas, diversificação na renda dos produtores e produção de massa seca para sustentabilidade da agricultura. $O$ objetivo deste trabalho foi avaliar o desempenho agronômico e o teor de nitrogênio da cultura do milho consorciado com forrageiras dos gêneros Panicum e Brachiaria. O delineamento experimental foi o de blocos casualizados, com quatro repetições. O experimento foi constituído de oito tipos de consórcio do milho com: Panicum maximum cv. 'Tanzânia', semeado simultaneamente (MTS) ou por ocasião da adubação nitrogenada de cobertura do milho (MTC); Panicum maximum cv. 'Mombaça', semeado simultaneamente (MMS) ou por ocasião da adubação nitrogenada de cobertura (MMC); Brachiaria brizantha cv. ' $M G-5$ ', semeado simultaneamente (MBS) ou por ocasião da adubação nitrogenada de cobertura (MBC); Brachiaria ruziziensis, semeado simultaneamente (MRS) ou por ocasião da adubação nitrogenada de cobertura (MRC), além do cultivo do milho sem consorciação (MSC). Quando a cultura do milho atingiu o estádio V6, procedeu-se à adubação de cobertura com $100 \mathrm{~kg}$ $h a^{-1}$ de $N$ para os 9 tratamentos. Os consórcios de forrageiras dos gêneros Panicum e Brachiaria com o milho não afetam o teor $N$ foliar, os componentes de produção e a produtividade de grãos de milho, quando comparados com o cultivo solteiro. As maiores produtividades de massa seca das forrageiras foram nos consórcios semeados na ocasião da adubação nitrogenada de cobertura do milho.

Palavras-chave: Zea mays, Panicum spp., Brachiaria spp., sistema plantio direto.

\section{ABSTRACT}

The intercropped between cultures lead to competition for production factors such as water, light and nutrients, however currently is common for integrated cultivation of corn for forage recovery and renovation of degraded areas, diversification of the producers income and production of dry matter for no-tillage system. The objective of this work was to evaluate the agronomic performance and nitrogen content of corn intercropped with forage of the genuse Brachiaria and Panicum. The experimental design was a randomized complete block with four repetitions. The experiment consisted of eigth treatments types of corn intercropped with: Panicum maximum $c v$. 'Tanzania' sowed simultaneously (MTS) or for occasion of the nitrogen fertilization at covering (TCM); Panicum maximum $\mathrm{cv}$. 'Mombaça' sowed simultaneously (MMS) or for occasion of the nitrogen fertilization at covering (MMC); Brachiaria brizantha $c v$. 'MG-5' sowed simultaneously (MBS) or for occasion of the nitrogen fertilization at covering (MBC); Brachiaria ruziziensis sowed simultaneously (MRS) or for occasion of the nitrogen fertilization at covering (MRC), besides the corn without intercropping (MSC). When the corn reached the V6 stage, proceeded the fertilization at covering with $100 \mathrm{~kg} \mathrm{ha}^{-1} \mathrm{~N}$ for the 9 treatments. The intercropped of forage of the genuse Brachiaria and Panicum with corn did not affect the $N$ leaf content, yield components and grain yield in relation to corn cropping. The highest dry matter yields of the forages were in the consortium sown at the occasion of the corn nitrogen fertilization at covering.

Key words: Zea mays, Panicum ssp., Brachiaria ssp., no-tillage system.

\section{INTRODUÇÃO}

A região do Cerrado, com 205 milhões de hectares, transformou-se na principal área de produção de carne e grãos do Brasil (VILELA et al., 2001). No entanto, o monocultivo e outras práticas culturais inadequadas têm causado perda

'Faculdade de Engenharia, Universidade Estadual Paulista (UNESP), Campus de Ilha Solteira, CP 31, 15385-000, Ilha Solteira, SP, Brasil. E-mail: mcmtf@yahoo.com.br. *Autor para correspondência. 
de produtividade, degradação do solo e dos recursos naturais (MACEDO, 2009). As causas possíveis para degradação das pastagens vão desde o manejo incorreto, processos erosivos por ações climáticas ou humanas, até a mudança natural da fertilidade do solo pela perda de nutrientes por exportação e/ou lixiviação.

A degradação do solo prejudica a produção agrícola, favorece o aparecimento de espécies espontâneas e diminui a cobertura vegetal, ocasionando erosão. Além disso, a não aplicação de práticas adequadas na formação e manutenção das pastagens, tais como manejo incorreto do solo, sem reposição de nutrientes, acelera o processo de degradação (OLIVEIRA; YOKOYAMA, 2003). Assim, uma das melhores opções para recuperação de pastagens degradadas, e que potencializa a produtividade na pecuária e de grãos, é o sistema de Integração Lavoura-Pecuária (ILP), que se adapta muito bem ao bioma cerrado (VILELA et al., 2011).

Para o meio ambiente, onde é cada vez maior a pressão por técnicas de cultivo autossustentáveis, a ILP contribui para a redução dos impactos ambientais decorrentes das atividades agrícolas. Avaliações feitas por GALHARTE \& CRESTANA (2010) mostraram efeito satisfatório da Integração Lavoura-Pecuária no âmbito da conservação ambiental.

A ILP pode ser definida como um sistema de produção que alterna, na mesma área, o cultivo de pastagens anuais ou perenes, destinadas à produção animal, e culturas destinadas à produção vegetal, sobretudo grãos. É importante considerar nesse conceito que a ILP é considerada como um sistema de produção, em que vários fatores biológicos, econômicos e sociais se inter-relacionam e determinam a sua sustentabilidade (BALBINOT JUNIOR, 2009). Por isso, esse sistema tem despertado maior interesse de pesquisadores nos últimos anos.

Os objetivos da integração são variados, pois, na exploração agrícola, objetiva-se a quebra do ciclo das pragas, doenças e plantas daninhas, redução via supressão física ou alelopática, de doenças das plantas cultivadas com origem no solo, melhoria na conservação de água, redução na amplitude térmica no solo e a possibilidade de agregar valores ao sistema (KLUTHCOUSKI \& YOKOYAMA, 2003). Na atividade pecuária, os objetivos vão desde a recuperação de pastagens degradadas, a manutenção de altas produtividades das pastagens e, principalmente, a produção de forrageira na entressafra e palhada em quantidade e qualidade para implantação ou manutenção do Sistema de Semeadura Direta (ALVARENGA et al., 2006).

O Sistema Santa Fé fundamenta-se na produção consorciada de culturas de grãos, especialmente o milho, o sorgo ou o milheto, com forrageiras tropicais, principalmente as do gênero Brachiaria e Panicum, tanto no Sistema de Semeadura Direta quanto no sistema convencional, em áreas de lavoura com solo parcial ou devidamente corrigido (KLUTHCOUSKI et al., 2000). A cultura do milho se destaca, no contexto da ILP, devido às inúmeras aplicações que esse cereal tem dentro da propriedade agrícola, quer seja na alimentação animal na forma de grãos ou de forragem verde ou conservada (rolão, silagem), na alimentação humana ou na geração de receita mediante a comercialização da produção excedente. Outro ponto importante são as vantagens comparativas do milho em relação a outros cereais ou produtoras de fibras, no que diz respeito ao seu consórcio com capins. Uma das vantagens é a competitividade no consórcio, visto que o porte alto das plantas de milho exerce, depois de estabelecidas, grande pressão de supressão sobre as demais espécies que crescem no mesmo local. A altura de inserção da espiga permite que a colheita seja realizada sem maiores problemas, pois a colheita mais alta da plataforma diminui os riscos de embuchamento (ALVARENGA et al., 2006).

De acordo com OLIVEIRA (2001), as forrageiras do gênero Brachiaria são as mais utilizadas em consórcio com a cultura do milho, destacam-se por apresentar excelente adaptação aos solos de baixa fertilidade, fácil estabelecimento e considerável produção de biomassa durante o ano, proporcionando excelente cobertura vegetal do solo. Pela sua agressividade e resistência, é também considerada importante competidora com espécies daninhas das culturas anuais.

Vários trabalhos realizados com $\mathrm{O}$ consórcio milho e forrageiras mostraram que, na média, a presença da forrageira reduziu a produtividade em aproximadamente 5\% (AIDAR, 2003; FREITAS et al., 2005). Contudo, verifica-se que, em vários casos, não há diferenças significativas entre o milho solteiro e o consorciado. Vale ressaltar que os diferentes resultados estão associados à combinação de vários fatores, como a população da forrageira, a época de sua implantação, os arranjos de semeadura, a presença de espontâneas, a aplicação de herbicidas, a fertilidade do solo e as condições hídricas (ALVARENGA et al., 2006).

Com base no exposto, o objetivo deste trabalho foi avaliar o desempenho agronômico e o teor de nitrogênio da cultura do milho consorciado com forrageiras dos gêneros Panicum e Brachiaria e a produtividade de matéria seca das forrageiras após o consórcio com o milho. 


\section{MATERIAL E MÉTODOS}

O experimento foi conduzido na safra 2009/2010, em área experimental pertencente à Faculdade de Engenharia - UNESP, localizada no município de Selvíria - MS, entre a latitude de $20^{\circ} 18^{\prime} \mathrm{S}$ e a longitude de $52^{\circ} 39^{\prime} \mathrm{W}$, com altitude de $335 \mathrm{~m}$. O solo foi classificado como LATOSSOLO VERMELHO distrófico, textura argilosa, o qual foi originalmente ocupado por vegetação de cerrado e está sendo cultivado por culturas anuais há mais de 25 anos, sendo em SPD há oito anos (cultura anterior milho). O tipo climático é Aw, segundo Köppen, caracterizado como tropical úmido com estação chuvosa no verão e seca no inverno. A temperatura média anual é de $23,5^{\circ} \mathrm{C}$, a precipitação pluvial média anual é de $1370 \mathrm{~mm}$, com umidade relativa do ar média anual entre 70 e $80 \%$. Durante a condução do experimento, foram mensuradas a precipitação pluvial (mm), umidade relativa do ar (\%) e as temperaturas $\left({ }^{\circ} \mathrm{C}\right)$ máxima, média e mínima (Figura 1 ).

Os atributos químicos iniciais na camada de 0 a $0,20 \mathrm{~m}$ do solo da área experimental foram, respectivamente: $20 \mathrm{mg} \mathrm{dm}^{-3}$ de $\mathrm{P}$ : (resina) $2,2 \%$ de $\mathrm{MO}$, pH em $\mathrm{CaCl}_{2}$ de 4,8; teores de $\mathrm{K}, \mathrm{Ca}, \mathrm{Mg}, \mathrm{H}+\mathrm{Al}$ e Al, respectivamente, de 3,$6 ; 20 ; 10 ; 38 \mathrm{e}^{2} \mathrm{mmol}_{\mathrm{c}} \mathrm{dm}^{-3}$, valores de 33,6 e 71,6 $\mathrm{mmol}_{\mathrm{c}} \mathrm{dm}^{-3} \mathrm{de} \mathrm{SB} \mathrm{e} \mathrm{CTC}$, respectivamente, e saturação por bases de $47 \%$.

$\mathrm{O}$ delineamento experimental foi $\mathrm{o}$ de blocos casualizados, com quatro repetições.
O experimento foi constituído de oito tipos de consórcio da cultura do milho com: Panicum maximum cv. 'Tanzânia', semeado simultaneamente (MTS) ou por ocasião da adubação nitrogenada de cobertura do milho (MTC); Panicum maximum cv. 'Mombaça', semeado simultaneamente (MMS) ou por ocasião da adubação nitrogenada de cobertura (MMC); Brachiaria brizantha cv. 'MG-5', semeado simultaneamente (MBS) ou por ocasião da adubação nitrogenada de cobertura (MBC); Brachiaria ruziziensis, semeado simultaneamente (MRS) ou por ocasião da adubação nitrogenada de cobertura (MRC), além do cultivo do milho sem consorciação (MSC). Quando a cultura do milho atingiu o estádio V6, procedeu-se à adubação de cobertura com $100 \mathrm{~kg}$ ha $^{-1}$ de $\mathrm{N}$ para os 9 tratamentos.

As dimensões das parcelas foram de $25 \mathrm{~m}$ de comprimento com 4 linhas de milho espaçadas de $0,90 \mathrm{~m}$, perfazendo $90 \mathrm{~m}^{2}$ e, para avaliação, como área útil da parcela, foram utilizadas as duas linhas centrais, desprezando-se $1 \mathrm{~m}$ em cada extremidade.

O híbrido simples utilizado foi o DKB 390 YG de ciclo precoce, semeado em 16/12/2009, com adubação de base realizada com $400 \mathrm{~kg} \mathrm{ha}^{-1}$ do formulado 04-30-10, igualmente para todos os tratamentos, baseada na análise do solo e na tabela de recomendação de adubação para a cultura do milho irrigado, para o Estado de São Paulo, conforme descrito em CANTARELLA et al. (1997).

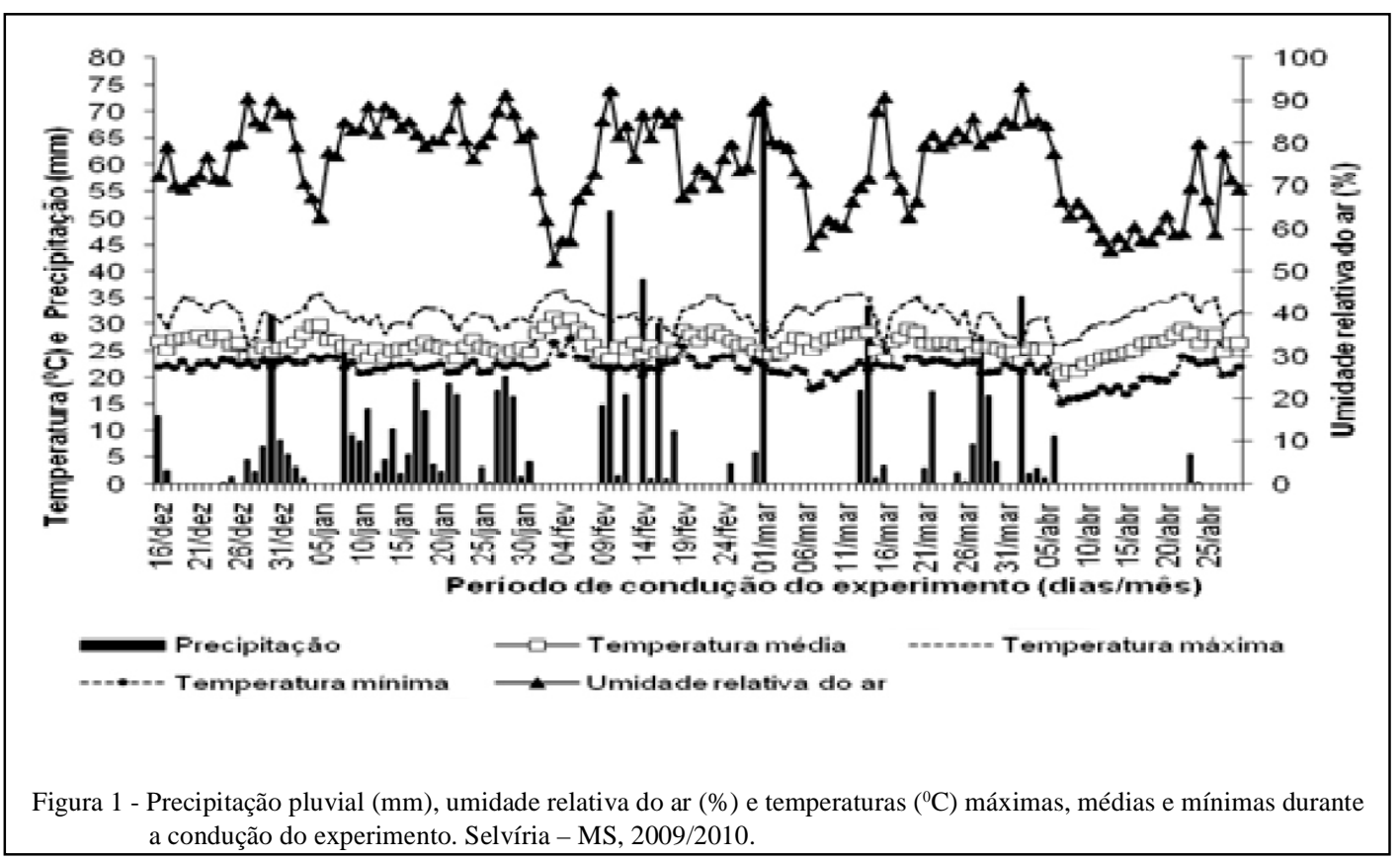

Ciência Rural, v.43, n.4, abr 2013. 
Nos consórcios estabelecidos na semeadura do milho, as sementes forrageiras foram semeadas na entrelinha da cultura, em espaçamento de $0,34 \mathrm{~m}$, na quantidade de $7 \mathrm{~kg}$ de sementes $\mathrm{ha}^{-1} \mathrm{com}$ VC de $76 \%$. A semeadura das forrageiras foi realizada por operação mecanizada com outra semeadoraadubadora de discos para sistema de semeadura direta (SSD). Enquanto que, nas modalidades em que as forrageiras foram semeadas por ocasião da adubação nitrogenada de cobertura (29/01/2010), as sementes foram misturadas ao adubo (ureia), minutos antes da semeadura, e acondicionadas no compartimento de fertilizante da adubadora. As sementes das forrageiras foram depositadas, mecanicamente, no solo, à profundidade de $0,03 \mathrm{~m}$ num espaçamento de $0,30 \mathrm{~m}$ distante da linha do milho. O fornecimento de água foi efetuado quando necessário por aspersão por meio de um sistema fixo de irrigação do pivô central, com controle pelo $\mathrm{Kc}$ de acordo com o desenvolvimento da cultura do milho.

Aos 20 dias após a emergência do milho (DAE), efetuou-se a aplicação da subdose do herbicida nicosulfuron, na dose de $8,0 \mathrm{~g}$ do i.a. ha ${ }^{-1}$, visando a amenizar o crescimento das forrageiras e, consequentemente, evitar a competição destas com o milho. Essas operações foram efetuadas com auxílio de um pulverizador tratorizado, com $12 \mathrm{~m}$ de comprimento de barra, utilizando-se ponta tipo leque 8001, espaçadas em 0,50m e com volume de calda de $300 \mathrm{~L} \mathrm{ha}^{-1}$.

Quando a cultura do milho atingiu o estádio V6 (seis folhas totalmente desdobradas), procedeu-se à adubação de cobertura e semeadura dos consórcios nessa modalidade de cultivo, aplicando-se $100 \mathrm{~kg} \mathrm{ha}^{-1}$ de $\mathrm{N}$, na forma de ureia ( $45 \%$ de $\mathrm{N}$ ). Essa quantidade seguiu as recomendações de CANTARELLA et al. (1997) para atingir a produtividade de 8-10t ha ${ }^{-1}$ de grãos, com classe de resposta alta para esse nutriente, sendo essa quantidade indicada para áreas nos primeiros anos sob SSD ou em cultivos antecessores de gramíneas.

No período de florescimento feminino do milho, foram coletadas 20 folhas da inserção da espiga principal (terço médio da folha) por parcela para avaliação do teor de N (MALAVOLTA et al., 1997). A colheita manual do milho foi realizada em 29/04/2010, correspondendo a 127 DAE. Foram coletadas 10 espigas de milho por parcela para as avaliações: a) População de plantas por hectare (PoPl); b) Número de espigas por hectare (NE); c) Número de fileiras de grãos por espiga (NFE); d) Número de grãos por fileira na espiga (NGF); e) Número de grãos por espiga (NGE); e f) Massa de 100 grãos (M100G), a 13\% de base úmida, determinada na ocasião da colheita; g) Produtividade de grãos (PG), determinada pela coleta das plantas contidas nas duas linhas centrais de cada parcela. Após a trilha mecânica, os grãos foram quantificados quanto a sua massa por parcela e os dados transformados em $\mathrm{kg}$ $\mathrm{ha}^{-1}$, a $13 \%$ (base úmida).

Com relação à produtividade de massa seca (PMS) das forrageiras, foi determinada cinco dias após a colheita do milho, sendo ceifadas em $1 \mathrm{~m}^{2}$ da parcela com auxílio de um quadrado de metal de 1x1m, a uma altura de $0,25 \mathrm{~m}$ da superfície do solo. Após o corte, as forrageiras foram levadas para estufa com circulação de ar forçada, com temperatura de $65^{\circ} \mathrm{C}$, por cerca de 72 horas, e, após quantificados, os dados foram transformados em $\mathrm{kg} \mathrm{ha}^{-1}$.

Utilizou-se para análise estatística o programa SISVAR. Os dados foram submetidos à análise de variância (teste F) e as médias dos tratamentos foram comparadas pelo teste de Tukey a $5 \%$ de probabilidade.

\section{RESULTADOS E DISCUSSÃO}

Não houve diferença significativa para o teor $\mathrm{N}$ foliar entre o cultivo do milho solteiro e as diferentes modalidades de consórcio com forrageiras dos gêneros Panicum e Brachiaria, demonstrando a não competição das forrageiras com o milho em consórcio sobre a absorção desse nutriente. Deve-se ressaltar também que os teores de $\mathrm{N}$ foliares ficaram dentro da faixa adequada (27 a $35 \mathrm{~g} \mathrm{~kg}^{-1}$ de MS), como descrito para o milho por CANTARELLA et al. (1997).

Os componentes de produção do milho (população de plantas por hectare, número de espigas por hectare, número de fileiras por espiga, número de grãos por fileira na espiga, número de grãos na espiga e massa de 100 grãos) não foram influenciados significativamente pelo consórcio com as forrageiras (Tabela 1). Por outro lado, em trabalho realizado por BORGHI \& CRUSCIOL (2007), o número de grãos e a massa de grãos por espiga foram influenciados pelas modalidades de cultivo, sendo que o cultivo do milho com capim-mombaça, consorciado, concomitantemente, à semeadura, proporcionou os menores valores, provavelmente pela maior competitividade ocasionada durante o período de desenvolvimento das espécies.

Em trabalho semelhante, PARIZ et al. (2011) constataram que o número de grãos por espiga e a massa de 100 grãos foram influenciados pelos consórcios das forrageiras semeadas simultaneamente com o milho, atribuindo tal fato à maior competição 
Tabela 1 - Teor de N foliar, componentes de produção e produtividade da cultura do milho consorciado em diferentes modalidades com forrageiras dos gèneros Panicum e Brachiaria e produtividade de matéria seca das forrageiras após o consórcio com a cultura do milho. Selvíria-MS, 2009/2010.

\begin{tabular}{|c|c|c|c|c|c|c|c|c|c|}
\hline Trat. $^{*}$ & TNF** (g kg ${ }^{-1}$ de M.S. $)$ & PoPl & NE ha $^{-1}$ & $\mathrm{NFE}$ & NGF & NGE & $\mathrm{M} 100 \mathrm{G}(\mathrm{g})$ & PG $\left(\mathrm{kg} \mathrm{ha}^{-1}\right)$ & $\operatorname{PMS}\left(\mathrm{kg} \mathrm{ha}^{-1}\right)$ \\
\hline $1-\mathrm{MTS}$ & $31,30^{\mathrm{ns}}$ & $48889^{\text {ns }}$ & $50000^{\mathrm{ns}}$ & $16,25^{\mathrm{ns}}$ & $36,75^{\mathrm{ns}}$ & $596,33^{\mathrm{ns}}$ & $32,03^{\text {ns }}$ & $8263^{\mathrm{ns}}$ & $825 \mathrm{abc}$ \\
\hline $2-\mathrm{MTC}$ & 31,82 & 46111 & 50000 & 16,15 & 35,10 & 567,14 & 32,79 & 6945 & $987 \mathrm{ab}$ \\
\hline $3-\mathrm{MMS}$ & 31,62 & 51111 & 51111 & 15,40 & 37,00 & 566,00 & 33,66 & 8020 & $687 \mathrm{c}$ \\
\hline $4-\mathrm{MMC}$ & 29,90 & 45000 & 48333 & 16,13 & 35,57 & 595,61 & 31,35 & 6318 & $1087 \mathrm{a}$ \\
\hline $5-\mathrm{MBS}$ & 38,35 & 53889 & 51667 & 16,10 & 37,00 & 573,58 & 32,03 & 7834 & $675 \mathrm{c}$ \\
\hline $6-\mathrm{MBC}$ & 29,90 & 52222 & 54444 & 15,55 & 35,50 & 552,26 & 33,08 & 7593 & $1000 \mathrm{ab}$ \\
\hline $7-\mathrm{MRS}$ & 29,72 & 51667 & 50000 & 16,00 & 36,05 & 575,12 & 32,12 & 8224 & $762 \mathrm{bc}$ \\
\hline $8-\mathrm{MRC}$ & 30,82 & 47778 & 50000 & 14,65 & 34,75 & 510,87 & 34,41 & 7136 & $1012 \mathrm{ab}$ \\
\hline $9-\mathrm{MCS}$ & 28,27 & 53889 & 47222 & 16,00 & 34,75 & 595,61 & 33,69 & 6750 & ----- \\
\hline D.M.S. & 10,29 & 13251 & 12276 & 2,38 & 4,36 & 107,49 & 6,46 & 2339 & 302 \\
\hline $\mathrm{CV}(\%)$ & 13,59 & 11,04 & 10,15 & 6,27 & 5,07 & 7,90 & 8,20 & 13,05 & 6,17 \\
\hline
\end{tabular}

${ }^{\mathrm{ns}}$ médias não diferem significativamente pelo teste $\mathrm{F}$ a $5 \%$.

*:* 1 - MTS (Milho + P. maximum cv. 'Tanzânia', semeados simultaneamente); 2 - MTC (Milho + P. maximum cv. 'Tanzânia', semeado por ocasião da adubação nitrogenada de cobertura); 3 - MMS (Milho + P. maximum cv. 'Mombaça', semeados simultaneamente); 4 - MMC (Milho + P. maximum cv. 'Mombaça', semeado por ocasião da adubação nitrogenada de cobertura); 5 - MBS (Milho + B. brizantha cv. 'Marandu', semeados simultaneamente); 6- MBC (Milho + B. brizantha cv. 'Marandu', semeada por ocasião da adubação nitrogenada de cobertura); 7 - MRS (Milho + B. ruziziensis, semeados simultaneamente); 8 - MRC (Milho + B. ruziziensis, semeada por ocasião da adubação nitrogenada de cobertura); e 9 - MCS (Cultivo solteiro do milho).

${ }^{* * * *} \mathrm{TNF}$ = teor de $\mathrm{N}$ foliar; PoPl = população de plantas ha ${ }^{-1}$; NE ha ${ }^{-1}=$ Número de espigas ha $^{-1}$; NFE - Número de fíleiras por espiga; NGF = Número de grãos por fileira; NGE - Números de grãos por espiga; M100G = Massa de 100 grãos; PG = Produtividade de grãos; PMS = Produtividade de matéria seca das forrageiras.

entre as espécies nessa modalidade de consórcio. Nesse sentido, o capim-mombaça semeado simultaneamente pela sua maior exigência, principalmente em fertilidade do solo, foi a espécie que mais reduziu os valores desses componentes em relação aos demais consórcios. Entretanto, cabe ressaltar que, no trabalho em questão, as condições climáticas foram de pluviosidade inferior no período de desenvolvimento das culturas, quando comparado com o presente trabalho, que teve pluviosidade muito superior durante o desenvolvimento das plantas (Figura 1), o que pode ter amenizado o efeito de competição.

BORGHI \& CRUSCIOL (2007) também não verificaram influência no número de espigas de milho como no presente trabalho com espaçamento entrelinhas de $0,90 \mathrm{~m}$, no consórcio de $\boldsymbol{B}$. brizantha cv. 'Marandu' com a cultura do milho, demonstrando, nesse aspecto, a homogeneidade do híbrido de milho avaliado. Por sua vez, MELLO et al. (2007) trabalharam com consorciação de milho com $\boldsymbol{B}$. Brizantha e B. ruziziensis, em dois espaçamentos e diferentes modalidades de semeadura, e também não observaram diferenças significativas nos valores de população de plantas de milho em função das modalidades de semeadura.
Na tabela 1, comparando-se a produtividade de grãos do milho solteiro e do milho consorciado com forrageiras dos gêneros Panicum e Brachiaria, verifica-se que não houve diferença significativa entre os tratamentos, mesmo com médias superiores nos consórcios em relação ao milho solteiro. Porém, em trabalho realizado por CHIODEROLI et al. (2010), o consórcio de milho outonal com B. ruzizienses proporcionou maiores valores de produtividade de grãos, diferindo da B. brizantha, que apresentou menores valores, dada a maior interferência com o milho.

PARIZ et al. (2009) observaram efeito significativo dos consórcios na produtividade de grãos, e que a consorciação com o capim-mombaça semeado simultaneamente com o milho reduziu o estande e o número de espigas por hectare. Entretanto, na média dos demais consórcios com espécies forrageiras (capim-tanzânia, Brachiaria brizantha e ruziziensis) e modos de semeadura, houve efeito sinérgico para produtividade de grãos de milho, quando comparado com o cultivo solteiro. Por sua vez, BARDUCCI et al. (2009) concluíram que o cultivo simultâneo de milho com Panicum maximum cv. 'Mombaça' na semeadura comprometeu a produtividade de grãos, e que o melhor consórcio 
a ser utilizado, visando à utilização em sistemas de produção, foi o milho cultivado simultaneamente com Brachiaria brizantha cv. 'Marandu'.

Em trabalho realizado por PEQUENO et al. (2006), os autores verificaram que a B. brizantha semeada na linha juntamente com o milho e $\boldsymbol{B}$. brizantha semeada a lanço nas entre linhas aos 16, 32 e 48 dias após a semeadura do milho, não resultaram em efeito significativo sobre a produtividade de grãos e matéria verde do milho.

Cabe destacar que não houve diferença significativa quanto às modalidades de cultivo sobre a população final de plantas, embora no cultivo do milho solteiro tenha sido pouco maior. Essas menores populações no consórcio podem ter sido influenciadas pelo mecanismo de corte da semeadora que não foi eficiente no corte da cobertura vegetal presente na área, deixando assim algumas sementes entre a palha, sem contato com o solo.

Com relação à produtividade de matéria seca de forrageiras dos gêneros Panicum e Brachiaria, após o consórcio com a cultura do milho (Tabela 1), observa-se que houve diferença significativa entre as diferentes modalidades de consórcio com as forrageiras, sendo verificadas as maiores PMS para o consórcio MMC, porém, este não diferiu significativamente dos MTS, MTC, MBC e MRC. Já as menores PMS foram proporcionadas pelos consórcios MBS e MMS, porém não diferiram significativamente do MRS. Esses resultados podem ser explicados devido à aplicação da subdose do herbicida nicosulfuron, realizada 20 dias após a emergência do milho, visando a amenizar o crescimento das forrageiras e, consequentemente, evitar a competição destas com as plantas de milho, apenas nos consórcios estabelecidos em conjunto na semeadura do milho.

Em trabalho semelhante, realizado por PARIZ et al.(2011), verificou-se efeito das modalidades de consórcios na produtividade de massa seca (PMS) das forrageiras. A B. brizantha, em o consórcio na linha de semeadura do milho, foi a espécies que apresentou a menor PMS, entretanto, no presente trabalho, os consórcios foram estabelecidos nas entrelinhas da cultura do milho, tanto na semeadura conjunta quanto na adubação de cobertura. Cabe destaque que, pela maior competição do milho com as forrageiras em consórcio, as PMS foram baixas (entre 800 e $1200 \mathrm{~kg}$ $\mathrm{ha}^{-1}$ ), pois, como destacado por ALVARENGA et al. (2006), o milho tem crescimento rápido e, após estabelecido o consórcio, normalmente as forrageiras apresentam mudança de hábito de crescimento, com efeito de estiolamento (crescimento em altura) em detrimento ao hábito mais prostrado, normal para as espécies em questão.

\section{CONCLUSÃO}

Os consórcios das forrageiras com milho em diferentes épocas de semeadura dos gêneros Panicum e Brachiaria não afetam o teor N foliar, os componentes de produção e a produtividade de grãos em relação ao milho em cultivo solteiro no Cerrado. As maiores produtividades de massa seca das forrageiras foram nos consórcios semeados na ocasião da adubação nitrogenada de cobertura do milho.

\section{AGRADECIMENTOS}

À Fundação de Amparo à Pesquisa do Estado de São Paulo (FAPESP), pela bolsa de estudo concedida (Processo: 2009/12727-7).

\section{REFERÊNCIAS}

ALVARENGA, R.C. et al. A cultura do milho na integração lavoura-pecuária. Sete Lagoas - MG: Embrapa-CNPMS, 2006. 12p. (Circular Técnica 80).

BALBINOT JUNIOR, A.A. et al. Integração lavoura-pecuária: intensificação de uso de áreas agrícolas. Ciência Rural, Santa Maria, v.39, n.6, p.1925-1933, 2009. Disponível em: <http://www. scielo.br/pdf/cr/v39n6/a229cr838.pdf>. Acesso em: 23 abr. 2012. doi: 10.1590/S0103-84782009005000107.

BARDUCCI, R.S. et al. Produção de Brachiaria brizantha e Panicum maximum com milho e adubação nitrogenada. Archivos de Zootecnia, Córdoba, v.58, n.222, p.211-222, 2009.

BORGHI, E.; CRUSCIOL, C.A.C. Produtividade de milho, espaçamento e modalidade de consorciação com Brachiaria brizantha no SPD. Pesquisa Agropecuária Brasileira, Brasília, v.42, n.2, p.163-171, 2007. Disponível em: <http://www.scielo.br/ pdf/pab/v42n2/04.pdf >. Acesso em: 20 dez. 2011. doi: 10.1590/ S0100-204X2007000200004.

CANTARELlA, H. et al. Cereais. In: RAIJ, B. van et al. Recomendações de calagem e adubação para o Estado de São Paulo. Campinas: IAC, 1997. 285p. (Boletim técnico, 100).

CHIODEROLI, C.A. et al. Consorciação de braquiárias com milho outonal em plantio direto sob pivô central. Engenharia Agrícola, Jaboticabal, v.30, n.6, p.1101-1109, 2010. Disponível em: <http:// www.scielo.br/scielo.php?script=sci_abstract\&pid=S0100691620 $10000600011 \& \operatorname{lng}=\mathrm{pt} \& \mathrm{nrm}=\mathrm{iso} \&$ tlng $=\mathrm{pt}>$. Acesso em: 30 nov. 2011. doi: 10.1590/S0100-69162010000600011.

FREITAS, F.C.L. et al. Formação de pastagem via consórcio de Brachiaria brizantha com o milho para silagem no sistema de plantio direto. Planta Daninha, Viçosa, v.23, n.1, p.49-58, 2005. Disponível em: <http://www.scielo.br/scielo.php?script=sci_ abstract\&pid $=$ S0100-83582005000100007\&lng $=$ pt\&nrm $=$ is o\&tlng=pt $>$. Acesso em: 20 nov. 2011. doi: 10.1590/S010083582005000100007 .

Ciência Rural, v.43, n.4, abr, 2013. 
GALHARTE, C.A.; CRESTANA, S. Avaliação do impacto ambiental da integração lavoura pecuária: Aspecto conservação ambiental no cerrado. Revista Brasileira de Engenharia Agrícola e Ambiental, Campina Grande, v.14, n.11, p.1202-1209, 2010.

KLUTHCOUSKI, J.; AIDAR, H. Uso da integração lavoura-pecuária na recuperação de pastagens degradadas. In: KLUTHCOUSKI, J. et al. (Ed.). Integração lavoura-pecuária. Santo Antonio de Goiás: Embrapa Arroz e Feijão, 2003. p.185-223.

KLUTHCOUSKI, J.; YOKOYAMA, L.P. Opções de integração lavoura-pecuária. In: KLUTHCOUSKI, J. et al. (Ed.). Integração lavoura-pecuária. Santo Antônio de Goiás: Embrapa Arroz e Feijão, 2003. p.131-141.

KLUTHCOUSKI, J. et al. Sistema Santa Fé - Tecnologia Embrapa: integração lavoura-pecuária pelo consórcio de culturas anuais com forrageiras, em áreas de lavoura, nos sistemas direto e convencional. Santo Antonio de Goiás: Embrapa Arroz e Feijão, 2000. 28p. (Circular Técnica, 38).

MACEDO, M.C.M.M. Integração lavoura e pecuária: o estado da arte e inovações tecnológicas. Revista Brasileira de Zootecnia, Viçosa, v.38, supl. esp, p.133-146, 2009. Disponível em: <http:// www.scielo.br/scielo.php?script=sci_abstract\&pid=S1516359820 09001300015\&lng=pt\&nrm=iso\&tlng=pt>. Acesso em: 12 nov. 2011. doi: 10.1590/S1516-35982009001300015.

MALAVOLTA, E. et al. Avaliação do estado nutricional das plantas: princípios e aplicações. 2.ed. Piracicaba: Associação Brasileira para Pesquisa da Potassa e do Fosfato, 1997. 319p.

MELLO, L.M.M. et al. Integração agricultura pecuária em plantio direto: consorciação braquiaria e milho. In: CONGRESSO BRASILEIRO DE ENGENHARIA AGRÍCOLA, 36., 2007, Bonito, MG. Anais... Jaboticabal: Sociedade Brasileira de Engenharia Agrícola, 2007. 1 CD ROM.
OLIVEIRA, I.P. Palhada no sistema Santa Fé. Goiânia: EMBRAPA-CNPAF, 2001. 4p. (Informações Agronômicas, 93).

OLIVEIRA, I.P.; YOKOYAMA, L.P. Implantação e condução do sistema barreirão. In: KLUTHCOUSKI, J. et al. Integração lavoura-pecuária. Santo Antonio de Goiás: Embrapa Arroz e Feijão, 2003. Cap.9, p.265-302.

PARIZ, C.M. et al. Desempenhos técnicos e econômicos da consorciação de milho com forrageiras dos gêneros Panicum e Brachiaria em sistema de integração lavoura-pecuária. Pesquisa Agropecuária Tropical, Goiânia, v.39, n.4, p.360-370, 2009. Disponível em: <http://www.revistas.ufg.br/index.php/pat/article/ view/5651>. Acesso em: 03 out. 2011.

PARIZ, C.M. et al. Produtividade de grãos de milho e massa seca de braquiárias em consórcio no sistema de integração lavoura-pecuária. Ciência Rural, Santa Maria, v.41, n.5, p.875882, 2011. Disponível em: <http://www.scielo.br/pdf/cr/v41n5/ a942cr2241.pdf>. Acesso em: 03/out. 2011. doi: 10.1590/S010384782011000500023

PEQUENO, D.N. et al. Efeito da época de semeadura da Brachiaria brizantha em consórcio com o milho, sobre caracteres agronômicos da cultura anual e da forrageira em Gurupi, estado do Tocantins. Amazônia: Ciência \& Desenvolvimento, Belém, v.2, n.3, p.127-133, 2006. Disponível em: <http://www.basa.com br/bancoamazonia2/Revista/edicao_03/Efeito_Epoca_Semeadur. pdf>. Acesso em: 25 jan. 2012.

VILELA, L. et al. Benefícios da integração entre lavoura e pecuária. Planaltina: Embrapa, 2001. 20p.

VILELA, L. et al. Sistemas de integração lavoura-pecuária na região do Cerrado. Pesquisa Agropecuária Brasileira, Brasília, v.46, n.10, p.1127-1138. 2011. 